\title{
Predicting stage 2 of calving in Holstein-Friesian heifers
}

\author{
K. Lange, C. Fischer-Tenhagen, and W. Heuwieser ${ }^{1,2}$ \\ Clinic for Animal Reproduction, Faculty of Veterinary Medicine, Freie Universität Berlin, Königsweg 65, 14163 Berlin, Germany
}

\begin{abstract}
The objective of this study was to predict stage 2 of calving in Holstein-Friesian heifers. Interobserver reliability and predictive values of relevant signs of imminent parturition (i.e., tail raising, stepping, clear and bloody vaginal discharge, turning the head toward the abdomen, and lying lateral with abdominal contractions) were determined. In the first experiment 32 heifers were included. Three investigators participated as observers in the study. They walked through the precalving pen in pairs and observed pregnant heifers ( $\geq 267 \mathrm{~d}$ pregnant). Cohen's kappa results for the interobserver reliability were between 0.51 and 0.91 . Thirty-seven Holstein-Friesian heifers were enrolled in the second experiment. Heifers were observed hourly for $24 \mathrm{~h} / \mathrm{d}$. Signs of imminent parturition that occurred were noted on a checklist. Compared with a precalving control period (4 d before calving), tail raising, clear vaginal discharge, and bloody vaginal discharge were more likely to occur during the last $24 \mathrm{~h}$ before calving. Two equations were built using the GENLINMIXED procedure to predict the hours until parturition. In version 1 , the absence or presence of each sign of imminent parturition except turning the head toward the abdomen was included. In version 2 , hours until parturition were estimated with the factors days of gestation, tail raising, and clear vaginal discharge. Relaxation of the broad pelvic ligaments and teat filling were evaluated twice per day. Prediction of calving with these parameters was not satisfying (positive predictive values were between 35.1 and $72.7 \%$ depending on the day of gestation). The possibility of excluding calving for the next $12 \mathrm{~h}$ was considerably higher, ranging from 88.5 to $97.1 \%$. These results indicate that predicting stage 2 of calving via direct observation of plausible signs is imprecise and therefore not recommendable.
\end{abstract}

\footnotetext{
Received September 20, 2016.

Accepted February 16, 2017.

${ }^{1}$ Corresponding author: w.heuwieser@fu-berlin.de

${ }^{2}$ Current address: Department of Population Medicine and Diagnostic Science, College of Veterinary Medicine, Cornell University, Ithaca, NY 14853.
}

Key words: calving, sign of parturition, prediction, dystocia

\section{INTRODUCTION}

Each calving is a crucial event in the reproductive cycle of a dairy cow and often a gateway for subsequent diseases. Optimal management and surveillance of calving, especially in heifers, are essential to prevent dystocia and stillbirth. This requires information on the exact time of calving. Parturition in cows may be divided into 3 stages (Noakes et al., 2001; Jackson, 2004). Stage 1 is characterized by opening of the cervix and the initiation of uterine contractions. The second stage starts with the dilation of the birth canal through the allantoic and amniotic sacs and ends with the expulsion of the fetus (Noakes et al., 2001). The release of the fetal membranes is the third stage of parturition (Noakes et al., 2001). The beginning of stage 2 is evident by the appearance of the amniotic sac outside the vulva (Schuenemann et al., 2011). The duration of stage 2 of calving is especially important for identifying problems in the calving process (Mee, 2004; Gundelach et al., 2009). The average time from the appearance of the amniotic sac to birth (i.e., the duration of stage 2 of calving) was $45.8 \mathrm{~min}$ for unassisted births in primiparous cows (Schuenemann et al., 2011). The median duration of stage 2 of calving was $42.7 \mathrm{~min}$ for unassisted heifers and $64.0 \mathrm{~min}$ for assisted heifers (Miedema et al., 2011a).

Although different approaches to predicting stage 2 of calving are practiced, no reliable method is available. Research has found that changes in behavior, such as restlessness, tail raising, and turning the head toward the abdomen (Miedema et al., 2011a; Barrier et al., 2012; Jensen, 2012), often occur 12 to $6 \mathrm{~h}$ before parturition. Moreover, vaginal discharge occurs (Schuenemann et al., 2011). Furthermore, the number of lying bouts increased during the last $6 \mathrm{~h}$ before parturition (Jensen, 2012).

Prior to the beginning of the study, a systematic literature search of clinical studies addressing signs of onset of calving was conducted. The databases PubMed (www.pubmed.gov) and ScienceDirect (www.sciencedi- 
Table 1. Signs of imminent parturition used in experiments 1 and 2

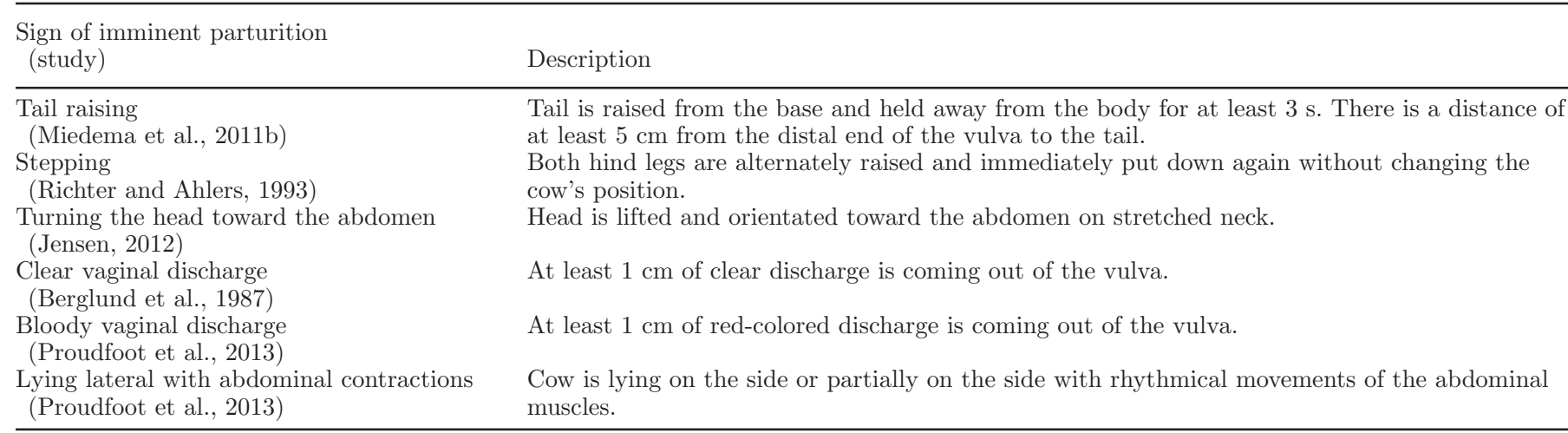

rect.com) were used to find articles written in English or German about physiological and behavioral indicators of the onset of calving. The subject headings "calving" AND "prediction" and "cattle" AND "calving behavior" were used. In a supplementary manual search, additional publications were recruited. The aim was to identify signs of imminent parturition (SIP) that are

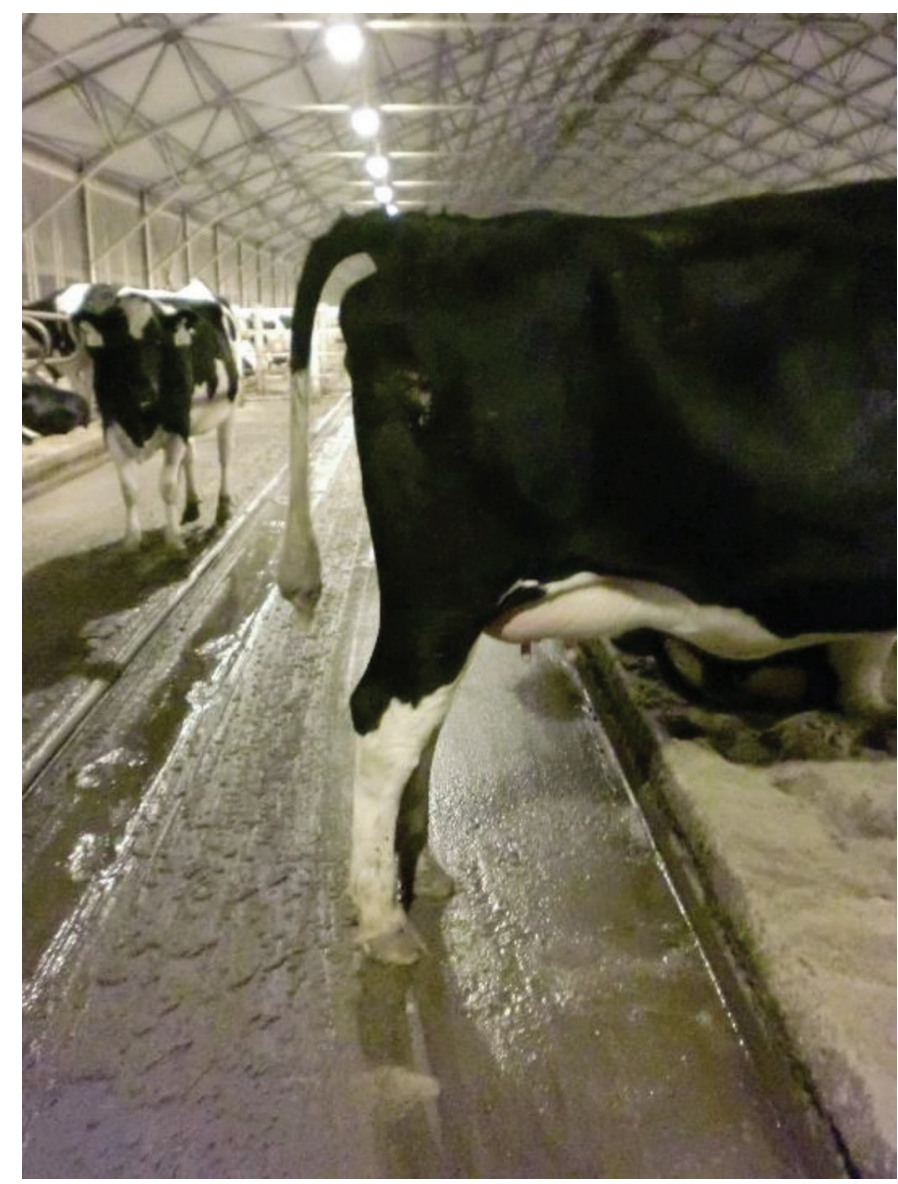

Figure 1. Tail raising. Color version available online. easy for farm personnel to recognize and predictive of the beginning of calving. Our focus was on developing a score sheet of SIP based on an hourly observation scheme. Finally, we considered tail raising (Figure 1; Miedema et al., 2011b), stepping (Richter and Ahlers, 1993), turning the head toward the abdomen (Jensen, 2012), clear vaginal discharge (Berglund et al., 1987), bloody vaginal discharge (Proudfoot et al., 2013), and lying lateral with abdominal contractions (Proudfoot et al., 2013) as plausible parameters for predicting the onset of calving (Table 1).

As a result of hormonal changes in preparation for calving, the broad pelvic ligaments relax, the udder enlarges, and teats fill up with colostrum (Berglund et al., 1987; Shah et al., 2006; Streyl et al., 2011). Monitoring cows antepartum is possible via direct observation, video surveillance, or the application of technical devices such as accelerometers (e.g., Ouellet et al., 2016), rumination sensors (e.g., Pahl et al., 2014), and temperature loggers (e.g., Burfeind et al., 2011). The clinical signs (i.e., relaxation of the broad pelvic ligaments, vaginal secretion, udder hyperplasia, udder edema, teat filling, tail relaxation, and vulva edema) alone and combined were evaluated to predict the time of parturition (Streyl et al., 2011). According to Streyl et al. (2011), the relaxation of the broad pelvic ligaments in combination with teat filling gave the best values for predicting either calving or no calving within $12 \mathrm{~h}$, with a sensitivity ranging from 73.9 to 89.1 and a specificity ranging from 60.0 to 78.9 depending on the cut-off value. Ouellet et al. (2016) used 3 automated devices to measure vaginal temperature, rumination and lying time, and lying bouts to predict the onset of calving. Prediction of calving within the next $24 \mathrm{~h}$ was possible with a combination of the 4 parameters with sensitivity and specificity of $77 \%$. Although monitoring the duration of the second stage of calving is especially important in preventing dystocia (Mee, 2004), the beginning of parturition is difficult to detect (Wehrend 
et al., 2006). In contrast, the absence of calving within the next 12 to $24 \mathrm{~h}$ can be accurately predicted by measuring a decrease in vaginal temperature and by the combination of pelvic ligament relaxation and teat filling (Burfeind et al., 2011; Saint-Dizier and ChastantMaillard, 2015).

For efficient labor management it is important to know when to start monitoring pregnant heifers and how often observation is necessary. Therefore, the objective of our study was to predict stage 2 of calving via direct observation. Specifically, we set out to evaluate the interobserver reliability for SIP and to determine the predictive values of SIP, changes in relaxation of the pelvic ligaments, and teat filling for calving.

\section{MATERIALS AND METHODS}

\section{Animals and Housing}

The study was conducted on a commercial dairy farm in Germany in October and November 2014. The farm milked 2,250 Holstein dairy cows with an average 305-d milk production of $10,346 \mathrm{~kg}$.

All heifers were introduced to a precalving pen approximately 3 wk before the estimated calving date. The precalving pen was located in a transition management facility, in which heifers were housed from 3 wk before to 3 wk after calving. Group composition was dynamic, with new heifers being introduced into the pen once per week. The heifers were housed in a freestall barn with 36 cubicles covered with a layer of at least $15 \mathrm{~cm}$ of sand. The maximum number of heifers in the barn was 36 . Within the pen the animals were able to move freely. When the calf's feet were visible outside the vulva, heifers were brought to an individual maternity pen with concrete topped with straw according to a standard operating procedure implemented by the farm. Within the pen the animals were able to move freely. Heifers were managed according to the guidelines set by the International Cooperation on Harmonization of Technical Requirements for Registration of Veterinary Medicinal Products (Hellmann and Radeloff, 2000).

\section{Experimental Design: Experiment 1}

In experiment 1 , the interobserver reliability of SIP was tested. A total of 32 heifers were included. Three investigators participated in the study (all female; 1 veterinarian and 2 students of animal science). One investigator participated for $2 \mathrm{wk}$, and the others participated for $1 \mathrm{wk}$ each. Before starting the experiments, the list of SIP was presented and discussed. A checklist with 6 items was developed for ticking off each rec- ognized SIP. Initially, training rounds were performed. For training and validation purposes, the investigators walked in pairs through the precalving pen and recorded and discussed the presence or absence of SIP of the average 16 heifers in the pen. During the test rounds, 2 of the investigators walked through the precalving pen hourly and observed the heifers for possible SIP. Results of this phase were not used for the analyses of interobserver reliability. Approximately 8 observation rounds were performed each day. In each observation round the investigators walked and stood next to each other to ensure a similar angle of view but documented their observations independently (i.e., without communication) on the checklist. Each heifer was observed for 15 s using a stopwatch.

\section{Statistical Analysis: Experiment 1}

To determine the interobserver reliability of SIP, Cohen's kappa was calculated using SPSS (SPSS Inc., Chicago, IL). The observation results of observers 1 and 2 (wk 1) and the observation results of observers 1 and 3 (wk 2) were included. A Cohen's kappa value was determined for each SIP listed in Table 1 except for bloody vaginal discharge and lying lateral with abdominal contraction because of an insufficient frequency of appearance. If the kappa value was between 0.41 and 0.6 , the strength of agreement was moderate. A kappa value between 0.61 and 0.8 and between 0.81 and 1 meant a substantial strength of agreement and an almost perfect strength of agreement, respectively (Landis and Koch, 1977).

\section{Experimental Design: Experiment 2}

Signs of Imminent Parturition. Six female investigators and 1 male investigator (5 veterinarians, 1 animal science student, and 1 veterinary technician) took part in experiment 2. All investigators were trained. The training implied discussing the list of SIP and implementing the checklist as described previously.

Thirty-seven clinically healthy Holstein-Friesian heifers $267 \pm 4 \mathrm{~d}$ postinsemination were included in the study. Heifers were checked for SIP each hour $24 \mathrm{~h} / \mathrm{d}$. On average, 13 heifers were observed in each observation round. Observation was divided into 2 shifts $(0800$ to $2000 \mathrm{~h}$ and 2000 to $0800 \mathrm{~h}$ ). The investigator walked through the pen, stopped behind a heifer, and observed the animal for $15 \mathrm{~s}$. Observation rounds were conducted as quietly as possible to avoid any disturbance of the heifers. Each SIP that appeared was marked off on the checklist. Each SIP could be scored only once for a given observation round. As soon as abdominal contractions started, heifers were monitored every $10 \mathrm{~min}$ 
to determine the time when the amniotic sac or the feet became visible (i.e., stage 2 of calving). These extra observations were not included in the SIP protocol and were conducted to determine the time of appearance of the amniotic sac or the feet. When the amniotic sac or the calf's feet appeared outside the vulva, the heifer was brought into the maternity pen and the time of parturition was documented.

Relaxation of the Broad Pelvic Ligaments and Teat Filling. In addition to SIP, we examined relaxation of the pelvic ligaments and teat filling because these findings had the best predictive value for predicting calving within $12 \mathrm{~h}$ (Streyl et al., 2011). At 0800 and $2000 \mathrm{~h}$, heifers were fixed in the head lockers for approximately $10 \mathrm{~min}$. The same investigator evaluated the relaxation of the broad pelvic ligaments and teat filling on a 4-point scale according to Streyl et al. (2011) twice a day (Table 2). The relaxation of the broad pelvic ligaments was estimated by manual palpation. The investigator pressed the fingertips of both hands except the thumbs onto the caudal edge of both pelvic ligaments of each heifer. Teat filling was determined by visual inspection of the teat skin of both rear quarters; the teats were not manually investigated. The different grades of plication of the teat skin were evaluated. A totally plicated teat was indicative of an empty teat, and a teat skin without any plication was considered to be a teat filled with colostrum. Points for relaxation of the pelvic ligaments and teat filling were added and summarized as a parturition score. We categorized data for relaxation of the pelvic ligaments and teat filling according to the day of gestation for every heifer (i.e., from d 269 until d 276 of gestation). The category d 272 of gestation, for example, included all heifers that were examined from this day on until calving.

\section{Statistical Analysis: Experiment 2}

Data were analyzed using Microsoft Excel (version 2013; Microsoft Corp., Redmond, WA), SPSS for Windows (version 22.0; SPSS Inc.), and MedCalc for Windows (version 12.0.3.0; MedCalc Software bvba, Ostend, Belgium). The occurrence of SIP was visual- ized with graphs in Microsoft Excel. We focused on the period $24 \mathrm{~h}$ before calving (Figure 2).

Precalving Control Observation. Before building the prediction model, we wanted to identify possible predictors for an imminent calving. Therefore, we evaluated differences between the occurrences of SIP in late pregnancy and compared these with the last 24 $\mathrm{h}$ before the onset of stage 2 calving. A binary logistic regression model was used that included time as the input variable and the occurrence of SIP as outcome variables. A $P$-value threshold of 0.1 was used to select parameters for elimination from the model. For the precalving control period in late pregnancy $(\mathrm{n}=30)$ we choose a period of $24 \mathrm{~h}$ on $\mathrm{d} 4$ before calving (i.e., the time $96-72 \mathrm{~h}$ before stage 2 ). Tail raising, turning the head toward the abdomen, stepping, clear vaginal discharge, and bloody vaginal discharge were included in the model, whereas lying lateral with abdominal contractions had to be excluded because it was not observed during the control period. In the last $24 \mathrm{~h}$ before calving, 35 heifers were included. Two heifers had to be excluded from the calculations because they were not completely observed during the last $24 \mathrm{~h}$.

Prediction Model. A general linear mixed model was built to calculate the effect of tail raising, stepping, clear vaginal discharge, bloody vaginal discharge, lying lateral with abdominal contractions, and days of gestation on hours until parturition. In a first approach, SIP were included in the model as fixed factors and cows were included as random factors, respectively. The model was based on 6,539 observations on 37 heifers. On average, 176.7 observations/heifer were conducted.

In a second approach, days of gestation was additionally included as fixed factor. With the estimates of the general linear mixed model we set up an equation to predict the hours until parturition. Signs of imminent parturition were coded as 0 (not seen) or 1 (seen), respectively.

The model took the following form:

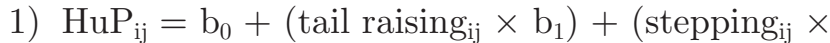
$\left.\mathrm{b}_{2}\right)+\left(\right.$ clear vaginal discharge $\left._{\mathrm{ij}} \times \mathrm{b}_{3}\right)+$ (bloody vaginal discharge $\left.\mathrm{e}_{\mathrm{ij}} \times \mathrm{b}_{4}\right)+$ (lying lateral with abdominal contractions $\left.\mathrm{ij}_{\mathrm{j}} \times \mathrm{b}_{5}\right)+\mathrm{u}_{\mathrm{i}}+\mathrm{e}_{\mathrm{ij}}$,

Table 2. Definition of the clinical signs relaxation of the broad pelvic ligaments and teat filling using a 4-point scale according to Streyl et al. (2011)

\begin{tabular}{|c|c|c|c|c|}
\hline \multirow[b]{2}{*}{ Clinical sign } & \multicolumn{4}{|c|}{ Parturition score } \\
\hline & 0 & 1 & 2 & 3 \\
\hline $\begin{array}{l}\text { Relaxation of the broad } \\
\text { pelvic ligaments }\end{array}$ & $\begin{array}{l}\text { Firm, no marginal } \\
\text { relaxation }(0-20 \%)\end{array}$ & $\begin{array}{l}\text { Mildly softened (up to } \\
50 \% \text { ) }\end{array}$ & $\begin{array}{l}\text { Totally softened but } \\
\text { palpable (up to } 100 \% \text { ) }\end{array}$ & $\begin{array}{l}\text { Totally softened, not } \\
\text { palpable }(100 \%)\end{array}$ \\
\hline Teat filling & Flaccid (none) & Slightly filled $(\sim 25 \%)$ & Moderately filled $(\sim 50 \%)$ & Completely filled $(\sim 100 \%)$ \\
\hline
\end{tabular}




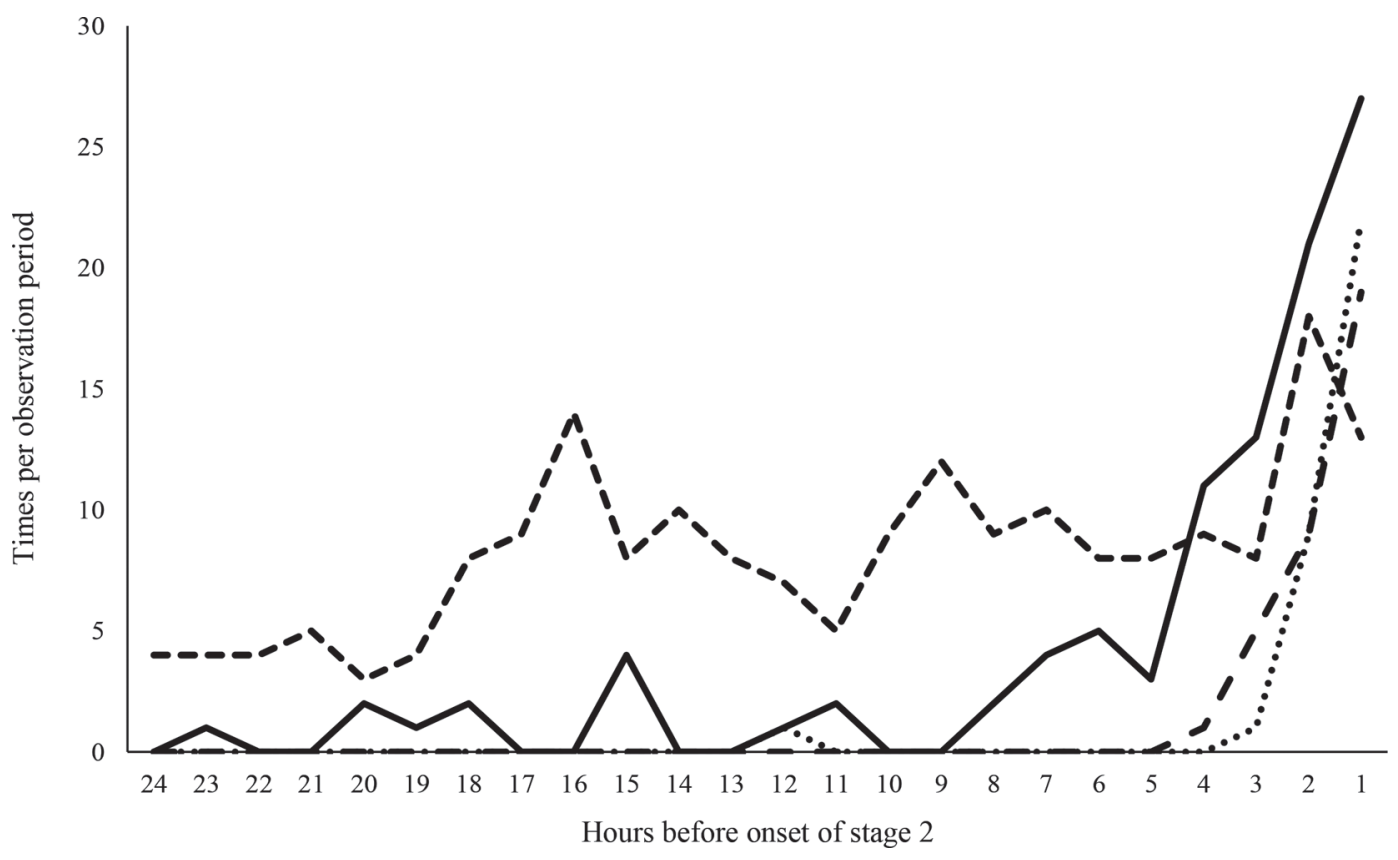

Figure 2. Occurrence of signs of imminent parturition: tail raising (solid line), clear vaginal discharge (short dashed line), bloody vaginal discharge (long dashed line), and lying lateral with abdominal contractions (dotted line) 24 h before stage 2.

2) $\mathrm{HuP}_{\mathrm{ij}}=\mathrm{b}_{0}+\left(\right.$ tail raising $\left.\mathrm{ij}_{\mathrm{j}} \times \mathrm{b}_{1}\right)+\left(\right.$ stepping $_{\mathrm{ij}} \times$ $\left.\mathrm{b}_{2}\right)+\left(\right.$ clear vaginal discharge $\left.\mathrm{i}_{\mathrm{ij}} \times \mathrm{b}_{3}\right)+($ bloody vaginal discharge $\left.\mathrm{ij}_{\mathrm{ij}} \times \mathrm{b}_{4}\right)+($ lying lateral with abdominal contractions $\left._{\mathrm{ij}} \times \mathrm{b}_{5}\right)+\left({\text { day of } \text { gestation }_{\mathrm{ij}}}\right.$ $\left.\times \mathrm{b}_{6}\right)+\mathrm{u}_{\mathrm{i}}+\mathrm{e}_{\mathrm{ij}}$,

where $\mathrm{HuP}_{\mathrm{ij}}$ is hours until parturition for the ith cow and the jth number of measurements, $b_{0}$ through $b_{6}$ are parameter estimates, $u_{i}$ is the random effect, and $e_{i j}$ is the residual error. The random effect and residual error were assumed to be normally distributed and independent from each other.

Observation Frequencies. A binary logistic regression model was used to calculate the effect of observation intervals on prediction of an imminent parturition within the next $6 \mathrm{~h}$. The time interval was chosen because the occurrence of SIP increased approximately $6 \mathrm{~h}$ before stage 2 . Thirty-seven calvings were included in the model. The occurrence of at least 2 out of 4 SIP (i.e., tail raising, clear vaginal discharge, bloody vaginal discharge, and lying lateral with abdominal contractions) at one observation time were considered as predictive of parturition. Odds ratios were calculated to compare hourly observation frequency with observation frequency each second hour until each sixth hour. Hourly observation frequency was the reference interval. The calculations were repeated, defining the $2-\mathrm{h}$ observation interval as reference.
Relaxation of the Pelvic Ligaments and Teat Filling. To determine the usability of a given sign for predicting calving, a receiver operating characteristic analysis was conducted using MedCalc. Receiver operating characteristic analysis evaluates the predictive value of a diagnostic test. The area under the curve (AUC) determines the diagnostic performance. A value of 1 means that there is a perfect separation of the test values of both groups (i.e., the test identifies each case of calving), whereas a value of 0.5 indicates that the test is not able to distinguish between both groups (Zweig and Campbell, 1993; i.e., calving and no calving). According to Greiner et al. (2000), a test with an AUC between 0.7 and 0.9 is moderately accurate, whereas a test with an AUC between 0.9 and 1 is highly accurate. The AUC was calculated for relaxation of the pelvic ligaments, teat filling, and a combination of relaxation of the pelvic ligaments for which the scores of the pelvic ligaments were single and double weighted (Streyl et al., 2011). The classification was the outcome, meaning the presence or absence of calving.

\section{RESULTS}

\section{Experiment 1}

A total of 32 heifers were observed to determine the interobserver reliability in wk 1 and 2. Cohen's kappa 
LANGE ET AL.

Table 3. Results of the interobserver reliability in experiment 1

\begin{tabular}{lcccc}
\hline Parameter & $\begin{array}{c}\text { Tail } \\
\text { raising }\end{array}$ & Stepping & $\begin{array}{c}\text { Turning } \\
\text { the head }\end{array}$ & $\begin{array}{c}\text { Clear vaginal } \\
\text { discharge }\end{array}$ \\
\hline Wk 1 & & & & 0.51 \\
$\quad$ Cohen's kappa value & 0.78 & 0.69 & 849 & 849 \\
Total no. of observations & 849 & 849 & 788 & 749 \\
Observer agreement & & & 22 & 56 \\
$\quad$ SIP $^{1}$ did not occur & 806 & 15 & 39 & 44 \\
SIP $^{1}$ occurred & 28 & 13 & 0.91 & 0.84 \\
Observer disagreement & 15 & 0.77 & 670 & 670 \\
Wk 2 & 0.89 & 670 & 617 & 554 \\
Cohen's kappa value & 670 & 651 & 45 & 88 \\
Total no. of observations & & 12 & 8 & 28 \\
Observer agreement & 21 & 7 & & \\
SIP did not occur & 5 & & & \\
SIP & & & & \\
Observer disagreement & & & & \\
\hline
\end{tabular}

${ }^{1} \mathrm{SIP}=$ signs of imminent parturition.

values were higher for all SIP in wk 2 compared with wk 1 (Table 3). Overall, reliability ranged between 0.507 and 0.912 .

\section{Experiment 2}

Signs of Imminent Parturition. Amniotic sac or calves' feet were seen $36.4 \pm 33.9$ min after the last regular observation of the SIP protocol. The occurrence of tail raising, bloody vaginal discharge, and lying lateral with abdominal contractions increased consistently within the last 4 observations before parturition (Figure 2). The first recognized SIP was clear vaginal discharge. Overall, it was observed 197 times out of 858 observations in the last $24 \mathrm{~h}$ before calving with hourly observation. In the second hour before stage 2, clear vaginal discharge was seen in 18 out of 37 heifers, which was the maximum occurrence of clear vaginal discharge in the last $24 \mathrm{~h}$. As clear vaginal discharge was found at least 3 times in the last $24 \mathrm{~h}$ before stage 2, clear vaginal discharge alone was not considered to be a suitable predictor. An increase in bloody vaginal discharge was found from the fourth to the last hour before the amniotic sac or the calves' feet were seen. Lying lateral with abdominal contractions occurred and increased from the third observation until stage 2. Tail raising increased consistently during the last $5 \mathrm{~h}$ until stage 2 and was the SIP that occurred most frequently in the last $6 \mathrm{~h}$ before parturition. Stepping and turning the head toward the abdomen did not occur often and did not increase before parturition. Therefore, both signs were disregarded.

Precalving Control Observation. A binary logistic regression analysis was conducted to determine the effect of observation time (i.e., late pregnancy vs. $24 \mathrm{~h}$ before stage 2) on the occurrence of SIP. Tail raising, clear vaginal discharge, and bloody vaginal discharge were more likely to occur $24 \mathrm{~h}$ before calving than in late pregnancy $(P \leq 0.001$; Table 4$)$. Stepping had a tendency to be more frequent in the period before calving than $4 \mathrm{~d}$ before $(P=0.073)$. Between both groups there was no difference for turning the head toward the abdomen $(P=0.331)$. Six out of 10 heifers that stepped calved within the next $24 \mathrm{~h}$ (odds ratio $=1.696)$. Seven out of 10 heifers showing tail raising or clear vaginal discharge calved within $24 \mathrm{~h}$. A heifer with bloody vaginal discharge had a 28.4 times greater probability of experiencing stage 2 during the next $24 \mathrm{~h}$.

Calving Prediction. In the first approach, tail raising, stepping, clear and bloody vaginal discharge, and lying lateral with abdominal contractions showed a significant influence on time to parturition $(P<$ 0.05; Table 5). Turning the head toward the abdomen showed a tendency to influence the outcome variable

Table 4. Binary logistic regression for signs of imminent parturition

\begin{tabular}{lccr}
\hline Sign of imminent parturition & Odds ratio & $95 \%$ CI & $P$-value \\
\hline Tail raising & 2.506 & $1.428-4.398$ & 0.001 \\
Stepping & 1.696 & $0.952-3.021$ & 0.073 \\
Head toward abdomen & 1.382 & $0.720-2.656$ & 0.331 \\
Clear vaginal discharge & 2.02 & $1.538-2.654$ & $\leq 0.001$ \\
Bloody vaginal discharge & 28.475 & $3.881-208.914$ & 0.001 \\
\hline
\end{tabular}


Table 5. Effect of signs of imminent parturition on hours until parturition

\begin{tabular}{|c|c|c|c|c|c|}
\hline Variable & $\begin{array}{c}\text { Estimate }^{1} \\
\text { (h until parturition) }\end{array}$ & $\mathrm{SE}^{2}$ & \multicolumn{2}{|c|}{$95 \% \mathrm{CI}$} & $P$-value \\
\hline Constant & 98.0 & & & & \\
\hline No & Referent & & & & \\
\hline Yes & -38.0 & 5.3 & -48.5 & -27.6 & $<0.001$ \\
\hline \multicolumn{6}{|l|}{ Stepping } \\
\hline \multicolumn{6}{|c|}{ Clear vaginal discharge } \\
\hline No & Referent & & & & \\
\hline Yes & -25.8 & 2.7 & -31.0 & -20.5 & $<0.001$ \\
\hline \multicolumn{6}{|c|}{ Bloody vaginal discharge } \\
\hline No & Referent & & & & \\
\hline Yes & -51.9 & 12.6 & -76.5 & -27.3 & $<0.001$ \\
\hline \multicolumn{6}{|c|}{ Lying lateral with abdominal contractions } \\
\hline
\end{tabular}

${ }^{1}$ Model adjusted for the random effect of cow.

${ }^{2}$ Standard error of the estimate.

hours until parturition $(P=0.061)$ and was excluded from the final calculation. The occurrence of bloody vaginal discharge decreased hours until parturition approximately twice as much as clear vaginal discharge. Tail raising and stepping showed a similar influence on hours until parturition. A constant was calculated and each SIP that occurred decreased the constant. Finally, mean number of hours until parturition was calculated via multiplying the estimate of the GENLINMIXED model by 0 or 1 for each SIP and summing the constant:

Hours until parturition $=97.99+$ (tail raising $\times$ $-38.0)+$ (stepping $\times-37.65)+($ clear vaginal discharge $\times-25.78)+$ (bloody vaginal discharge $\times$ $-51.88)+$ (lying lateral with abdominal contractions $\times-30.52)$

For example, a heifer seen with tail raising and bloody vaginal discharge during 1 observation needed
$97.99+(-38 \times 1)+(-37.65 \times 0)+(-25.78 \times 0)+$ $(-51.88 \times 1)+(-30.52 \times 0)=8.1$ h until parturition.

In the second approach, tail raising, clear vaginal discharge, and day of gestation showed a significant influence on hours until parturition $(P<0.05)$ as presented in Table 6.

Observation Frequencies. No difference in detecting imminent parturition was found between hourly observation and observation every $2 \mathrm{~h}(P=0.139$; Table 7 ). The probability of detecting stage 2 calving decreased when the interval between observations increased. The probability of detecting stage 2 of calving was $4.09,9.17$, and 11.63 times higher when observing heifers each hour compared with observing heifers each 3,5 , or $6 \mathrm{~h}$, respectively. Considering a 2 -h observation interval as a reference, detecting imminent parturition was significantly higher compared with a $3-, 4-, 5-$, or 6-h observation interval, respectively.

Table 6. Effect of signs of imminent parturition and days of gestation on hours until parturition

\begin{tabular}{|c|c|c|c|c|c|}
\hline Variable & $\begin{array}{c}\text { Estimate }^{1} \\
\text { (h until parturition) }\end{array}$ & $\mathrm{SE}^{2}$ & \multicolumn{2}{|c|}{$95 \% \mathrm{CI}$} & $P$-value \\
\hline Constant & $6,286.6$ & & & & \\
\hline No & Referent & & & & \\
\hline Yes & -1.7 & 0.5 & -2.7 & -0.8 & $<0.001$ \\
\hline \multicolumn{6}{|c|}{ Clear vaginal discharge } \\
\hline \multicolumn{6}{|c|}{ Days of gestation } \\
\hline No & Referent & & & & \\
\hline Yes & -22.9 & 0.03 & -22.9 & -22.8 & $<0.001$ \\
\hline
\end{tabular}

${ }^{1}$ Model adjusted for the random effect of cow.

${ }^{2}$ Standard error of the estimate. 
Table 7. Binary logistic regression model describing the effect of observation intervals on recognizing stage 2 of calving

\begin{tabular}{lcccc}
\hline Observation frequency & Estimate & Odds ratio & $95 \%$ CI & $P$-value \\
\hline Each hour & Referent & Referent & & \\
Each second hour & -0.721 & 0.486 & $0.187-1.264$ & 0.139 \\
Each third hour & -1.401 & 0.246 & $0.100-0.608$ & 0.002 \\
Each fourth hour & -1.866 & 0.155 & $0.064-0.375$ & $\leq 0.01$ \\
Each fifth hour & -2.214 & 0.109 & $0.045-0.263$ & $\leq 0.01$ \\
Each sixth hour & -2.449 & 0.086 & $0.036-0.207$ & $\leq 0.01$ \\
\hline
\end{tabular}

Relaxation of the Pelvic Ligaments and Teat Filling. Heifers calved on average on d $275 \pm 4.84$ of gestation during the study $(\mathrm{n}=37)$. The duration of pregnancy ranged from $267 \mathrm{~d}(\mathrm{n}=2)$ to $286 \mathrm{~d}(\mathrm{n}=$ 1). The best results for the AUC were achieved when a combination of relaxed pelvic ligaments (double weighted) and teat filling (single weighted) was used. The AUC results ranged from 0.808 to 0.855 depending on the start of measurement (i.e., 269 to $276 \mathrm{~d}$ of gestation). An AUC of 0.8 determines that a calving heifer will have a higher parturition score than a noncalving one in $80 \%$ of the examinations (Zweig and Campbell, 1993).

Seventy-three percent of the heifers $(\mathrm{n}=27)$ had a parturition score $>5$ at the last examination before calving. The maximum sum of sensitivity and specificity was estimated to identify a suitable cut-off value for the parturition score. The cut-off value was $>5$ except for examinations from d 276 of gestation until calving (Table 8).

Sensitivity and specificity were 68.97 and $87.91 \%$, respectively, for predicting calving within $12 \mathrm{~h}$ for heifers
( $\mathrm{n}=29$ ) examined from d 269 until calving; the cut-off value was $>5$ in $35.1 \%$ of the cases (Table 8). Negative predictive values were considerably higher. The possibility of predicting the absence of calving was $96.8 \%$ considering 29 heifers examined from d 269 of gestation until parturition, a cut-off value of $>5$, a $68.97 \%$ sensitivity, and a $87.91 \%$ specificity.

\section{DISCUSSION}

Recognizing landmarks of stage 2 of calving (e.g., the appearance of the amniotic sac or the calves' feet) is important in evaluating the progress of the expulsion of the fetus (Schuenemann et al., 2011). Prevalence of dystocia varies in different studies but is considerably higher in heifers compared with multiparous cows (Meyer et al., 2001; Lombard et al., 2007). Hence, predicting stage 2 of calving is of major importance, especially for primiparous dams.

Moving heifers during late stage 1 of calving has been shown to prolong the duration of stage 2 (Proudfoot et al., 2013). Farm staff, however, brought heifers to the

Table 8. Results of a receiver operating characteristic analysis for predicting calving with the parameters pelvic ligaments and teat filling ${ }^{1}$

\begin{tabular}{|c|c|c|c|c|c|c|c|}
\hline $\begin{array}{l}\text { Days of } \\
\text { gestation }\end{array}$ & $\begin{array}{l}\text { No. of } \\
\text { calvings }\end{array}$ & AUC & $\begin{array}{l}\text { Cut-off } \\
\text { value }\end{array}$ & Sensitivity & Specificity & $+\mathrm{PV}$ & $-\mathrm{PV}$ \\
\hline 269 & 29 & $\begin{array}{l}0.846^{*} \\
(0.833-0.883)\end{array}$ & $>5$ & $\begin{array}{l}68.97 \\
(49.2-84.7)\end{array}$ & $\begin{array}{l}87.91 \\
(83.7-91.3)\end{array}$ & $\begin{array}{l}35.1 \\
(22.9-48.9)\end{array}$ & $\begin{array}{l}96.8 \\
(93.9-98.5)\end{array}$ \\
\hline 271 & 22 & $\begin{array}{l}0.837^{*} \\
(0.784-0.881)\end{array}$ & $>5$ & $\begin{array}{l}72.73 \\
(49.8-89.3)\end{array}$ & $\begin{array}{l}84.75 \\
(79.4-89.2)\end{array}$ & $\begin{array}{l}32.0 \\
(19.4-46.9)\end{array}$ & $\begin{array}{l}96.9 \\
(93.4-98.9)\end{array}$ \\
\hline 273 & 20 & $\begin{array}{l}0.823^{*} \\
(0.761-0.875)\end{array}$ & $>5$ & $\begin{array}{l}70.00 \\
(45.7-88.1)\end{array}$ & $\begin{array}{l}84.43 \\
(78.0-89.6)\end{array}$ & $\begin{array}{l}35.0 \\
(20.5-51.9)\end{array}$ & $\begin{array}{l}95.9 \\
(91.3-98.5)\end{array}$ \\
\hline 274 & 20 & $\begin{array}{l}0.814^{*} \\
(0.742-0.873)\end{array}$ & $>5$ & $\begin{array}{l}70.00 \\
(45.7-88.1)\end{array}$ & $\begin{array}{l}82.03 \\
(74.3-88.3)\end{array}$ & $\begin{array}{l}37.8 \\
(22.5-55.2)\end{array}$ & $\begin{array}{l}94.6 \\
(88.6-98.0)\end{array}$ \\
\hline 275 & 19 & $\begin{array}{l}0.844^{*} \\
(0.762-0.906)\end{array}$ & $>5$ & $\begin{array}{l}73.68 \\
(48.8-90.9)\end{array}$ & $\begin{array}{l}81.11 \\
(71.5-88.6)\end{array}$ & $\begin{array}{l}45.2 \\
(27.0-64.3)\end{array}$ & $\begin{array}{l}93.6 \\
(85.7-97.9)\end{array}$ \\
\hline 276 & 15 & $\begin{array}{l}0.808^{*} \\
(0.698-0.891)\end{array}$ & $>6$ & $\begin{array}{l}53.33 \\
(26.6-78.7)\end{array}$ & $\begin{array}{l}94.74 \\
(85.4-98.9)\end{array}$ & $\begin{array}{l}72.7 \\
(39.0-94.0)\end{array}$ & $\begin{array}{l}88.5 \\
(77.8-95.3)\end{array}$ \\
\hline
\end{tabular}

${ }^{1}$ Pelvic ligaments are double weighted. Values in parentheses are $95 \%$ CI. AUC $=$ area under the curve; + PV $=$ positive predictive value; $-\mathrm{PV}$ $=$ negative predictive value.

$* P<0.05$. 
calving pen during stage 2 of calving (i.e., as soon as the amniotic sac or the feet became visible). We consider this management practice to be critical because heifers showed some exploration behavior (sniffing, licking, vocalization) before lying down.

In our study, the interobserver reliability for the 4 SIP (i.e., tail raising, stepping, turning the head toward the abdomen, and clear vaginal discharge) was good or very good, except that for turning the head toward the abdomen in wk 1. This indicates that the list of SIP generated in combination with validation rounds is a useful tool for reaching good agreement for SIP if multiple observers are involved, which is usually the case on commercial dairy farms. Streyl et al. (2011) found similar kappa values for relaxation of the pelvic ligaments and teat filling (0.86 and 0.82, respectively).

In accordance with previous observations (Streyl et al., 2011), AUC results for the relaxation of the pelvic ligaments and teat filling were highest when the score of the pelvic ligaments was double weighted. Starting examination of relaxation of the pelvic ligaments and teat filling on d 270 of gestation led to an AUC (0.855) with sensitivity of $74.07 \%$ and specificity of $86.94 \%$. However, $36.4 \%$ of the heifers were correctly diagnosed. Because these test characteristics were not satisfactory, we suggest using relaxation of the pelvic ligaments and teat filling to exclude the possibility of calving, confirming Streyl et al. (2011). Approximately $97 \%$ of the heifers that were diagnosed as not calving did not calve during the next $12 \mathrm{~h}$. Knowing which heifer will not calve during the next $12 \mathrm{~h}$ facilitates monitoring and increases efficiency. Still, it is important to consider that the predictive value depends on the prevalence. In our data set prevalence varied between 8.6 and 20.8\% depending on the day of gestation chosen as the starting point.

In contrast to our expectation, we recognized much variation in the appearance and time of occurrence of SIP. Tail raising, bloody vaginal discharge, and lying lateral with abdominal contractions first occurred approximately $9 \mathrm{~h}$ before stage 2. Miedema et al. (2011a) observed a significant increase in the frequency and duration of tail raising during the last $12 \mathrm{~h}$ before parturition. Although we concentrated on short observation periods regarding the 12 last observations until stage 2, we could also see a clear increase in tail raising and found a significant difference compared with our control period.

It appears to be useful to differentiate between clear and bloody vaginal discharge. There was a significant difference between the occurrence of vaginal discharge in the calving period in contrast to the control period (Table 4), but clear vaginal discharge was found inter- mittently several days before parturition in 31 of 35 heifers. Conversely, bloody vaginal discharge occurred in the calving group during the last 4 observations before stage 2 and was observed just once in the control group. Jensen (2012) described an increase in turning the head toward the abdomen in the last $2 \mathrm{~h}$ before calving. We could not confirm this finding, nor did a significant difference exist between the control and the calving period. This controversy is potentially attributable to the different observational methods. It is obvious that a behavioral sign with a duration of a few seconds (e.g., turning the head toward the abdomen) is better detected during continuous observation than during repeated observations lasting $15 \mathrm{~s}$.

The recommendations for monitoring frequency of pregnant cows vary from 1 to $2 \mathrm{~h}$ (Gundelach et al., 2009; Schuenemann et al., 2011) to 3 to $6 \mathrm{~h}$ (Mee, 2004). Interestingly, our data showed a significant difference between hourly observation compared with 3 - to 6 -h observation intervals. There was no difference, however, between hourly observation compared with observation every second hour. Hence, we suggest observing pregnant heifers every $2 \mathrm{~h}$ for tail raising, clear and bloody vaginal discharge, and lying lateral with abdominal contractions. To observe the complete behavior repertoire for the time before parturition, cows have to be monitored continuously as implemented in several other studies (e.g., Miedema et al., 2011a; Barrier et al., 2012; Jensen, 2012). The scope of our study, however, was targeted toward field conditions. Therefore, we implemented direct observation periods at preset times to simulate common calving monitoring practices. Also, we limited observation time to $15 \mathrm{~s} /$ cow.

To our knowledge, an equation for the prediction of calving has not yet been developed. This is the first approach to using SIP to calculate time of expected calving on farms. Further research considering a larger sample size and different housing systems and breeds is warranted to increase robustness of the equation. After further expanding the database of SIP, we could imagine that this prediction model could be part of a technical application for farm personnel to easily and reliably predict stage 2 of calving.

\section{ACKNOWLEDGMENTS}

We gratefully thank the personnel of the dairy farm for their kind cooperation. Furthermore, we thank Veyx-Pharma and the staff of the Clinic for Animal Reproduction, Freie Universität Berlin, Germany, for their support during the study. Katrin Lange was partially funded by Tiergyn e.V., Berlin. 


\section{REFERENCES}

Barrier, A. C., M. J. Haskell, A. I. Macrae, and C. M. Dwyer. 2012 Parturition progress and behaviours in dairy cows with calving difficulty. Appl. Anim. Behav. Sci. 139:209-217.

Berglund, B., J. Philipsson, and O. Danell. 1987. External signs of preparation for calving and course of parturition in Swedish dairycattle breeds. Anim. Reprod. Sci. 15:61-79.

Burfeind, O., V. S. Suthar, R. Voigtsberger, S. Bonk, and W. Heuwieser. 2011. Validity of prepartum changes in vaginal and rectal temperature to predict calving in dairy cows. J. Dairy Sci. 94:5053-5061.

Greiner, M., D. Pfeiffer, and R. D. Smith. 2000. Principles and practical application of the receiver-operating characteristic analysis for diagnostic tests. Prev. Vet. Med. 45:23-41.

Gundelach, Y., K. Essmeyer, M. K. Teltscher, and M. Hoedemaker. 2009. Risk factors for perinatal mortality in dairy cattle: Cow and foetal factors, calving process. Theriogenology 71:901-909.

Hellmann, K., and I. Radeloff. 2000. International cooperation on harmonisation of technical requirements of veterinary medicinal products (VICH). Brussels, Belgium. Accessed Mar. 27, 2017. http://www.fda.gov/downloads/AnimalVeterinary/ GuidanceComplianceEnforcement/GuidanceforIndustry/ UCM052417.pdf.

Jackson, P. G. G. 2004. Normal birth. Pages 1-12 in Handbook of Veterinary Obstetrics. 2nd ed. W. B. Saunders, Oxford, UK.

Jensen, M. B. 2012. Behaviour around the time of calving in dairy cows. Appl. Anim. Behav. Sci. 139:195-202.

Landis, J. R., and G. G. Koch. 1977. The measurement of observer agreement for categorical data. Biometrics 33:159-174.

Lombard, J. E., F. B. Garry, S. M. Tomlinson, and L. P. Garber. 2007. Impacts of dystocia on health and survival of dairy calves. J. Dairy Sci. 90:1751-1760.

Mee, J. F. 2004. Managing the dairy cow at calving time. Vet. Clin. North Am. Food Anim. Pract. 20:521-546.

Meyer, C. L., P. J. Berger, K. J. Koehler, J. R. Thompson, and C. G. Sattler. 2001. Phenotypic trends in incidence of stillbirth for Holsteins in the United States. J. Dairy Sci. 84:515-523.

Miedema, H. M., M. S. Cockram, C. M. Dwyer, and A. I. Macrae. 2011a. Behavioural predictors of the start of normal and dystocic calving in dairy cows and heifers. Appl. Anim. Behav. Sci. 132:14-19.
Miedema, H. M., M. S. Cockram, C. M. Dwyer, and A. I. Macrae. 2011b. Changes in the behaviour of dairy cows during the $24 \mathrm{~h}$ before normal calving compared with behaviour during late pregnancy. Appl. Anim. Behav. Sci. 131:8-14.

Noakes, D. E., T. J. Parkinson, and G. C. W. England. 2001. Parturition and the care of parturient animals. Pages 155-187 in Arthur's Veterinary Reproduction and Obstetrics. 8th ed. W.B. Saunders, Oxford, UK.

Ouellet, V., E. Vasseur, W. Heuwieser, O. Burfeind, X. Maldague, and E. Charbonneau. 2016. Evaluation of calving indicators measured by automated monitoring devices to predict the onset of calving in Holstein dairy cows. J. Dairy Sci. 99:1539-1548.

Pahl, C., E. Hartung, A. Grothmann, K. Mahlkow-Nerge, and A Haeussermann. 2014. Rumination activity of dairy cows in the 24 hours before and after calving. J. Dairy Sci. 97:6935-6941.

Proudfoot, K. L., M. B. Jensen, P. M. Heegaard, and M. A. von Keyserlingk. 2013. Effect of moving dairy cows at different stages of labor on behavior during parturition. J. Dairy Sci. 96:1638-1646.

Richter, J., and D. Ahlers. 1993. Tiergeburtshilfe. Paul Parey, Berlin, Germany.

Saint-Dizier, M., and S. Chastant-Maillard. 2015. Methods and onfarm devices to predict calving time in cattle. Vet. J. 205:349-356.

Schuenemann, G. M., I. Nieto, S. Bas, K. N. Galvao, and J. Workman. 2011. Assessment of calving progress and reference times for obstetric intervention during dystocia in Holstein dairy cows. J. Dairy Sci. 94:5494-5501.

Shah, K. D., T. Nakao, and H. Kubota. 2006. Plasma estrone sulphate (E1S) and estradiol-17 beta (E-2 beta) profiles during pregnancy and their relationship with the relaxation of sacrosciatic ligament, and prediction of calving time in Holstein-Friesian cattle. Anim. Reprod. Sci. 95:38-53.

Streyl, D., C. Sauter-Louis, A. Braunert, D. Lange, F. Weber, and H. Zerbe. 2011. Establishment of a standard operating procedure for predicting the time of calving in cattle. J. Vet. Sci. 12:177-185.

Wehrend, A., E. Hofmann, K. Failing, and H. Bostedt. 2006. Behaviour during the first stage of labour in cattle: Influence of parity and dystocia. Appl. Anim. Behav. Sci. 100:164-170.

Zweig, M. H., and G. Campbell. 1993. Receiver operating characteristic (Roc) plots-A fundamental evaluation tool in clinical medicine. Clin. Chem. 39:561-577. 